Bài báo khoa học

\title{
Nghiên cứu phân vùng khí hậu nông nghiệp phục vụ mục đích chuyển đổi cơ cấu cây trồng tỉnh Tuyên Quang
}

\section{Nguyễn Thị Liễu ${ }^{*}$, Nguyễn Đăng Tiến ${ }^{2}$}

${ }^{1}$ Viện Khoa học Khí tượng Thủy văn và Biến đổi khí hậu; lieuminh2011@gmail.com

${ }^{2}$ Trường Đại học Sao Đỏ; dangtien.dhsd@gmail.com

*Tác giả liên hệ: lieuminh2011@gmail.com; Tel: +84-989316846

Ban Biên tập nhận bài: 16/3/2021; Ngày phản biện xong: 14/5/2021; Ngày đăng bài: $25 / 6 / 2021$

Tóm tắt: Nghiên cứu khí hậu ứng dụng là một trong những hướng nghiên cứu có tính thực tiễn cao nhằm phục vụ phát triển kinh tế theo hướng bền vững. Đồng thời, góp phần khai thác sử dụng hợp lý nguồn tài nguyên thiên nhiên, bảo vệ môi trường cho một vùng lãnh thổ nhất định để hướng tới sản xuất ngành nông nghiêp một cách hiệu quả. Bài báo áp dụng phương pháp phân vùng khí hậu nông nghiệp bằng công cụ Luset được tham số hóa các yếu tố khí tượng, thổ nhưỡng, địa hình. Kết quả tính toán cho thấy: Tỉnh Tuyên Quang được phân thành 4 vùng khí hậu nông nghiệp chính đó là: vùng rất thích nghi khoảng 281.406 ha, chiếm $48,5 \%$ tổng diện tích toàn tỉnh; Vùng thích nghi khoảng 164.088 ha, chiếm $28,3 \%$; Vùng ít thích nghi khoảng 70.813 ha, chiếm $12,2 \%$ và vùng không thích nghi khoảng 64.375 ha, chiếm 11,1\%.

Từ khóa: Phân vùng; Khí hậu nông nghiệp; Công cụ Luset.

\section{Mở đầu}

Nông nghiệp có mối quan hệ chặt chẽ đối với các điều kiện tự nhiên, trong đó khí hậu là yếu tố có tác động mạnh mẽ nhất đến sản xuất nông nghiệp. Yếu tố khí hậu chính được xác định cho hoạt động trồng trọt là: ánh sáng, nhiệt độ, độ ẩm [1-2, 4-8, 11-12]. Đây là những yếu tố không thể thiếu và không thay thế cho nhau được đối với sự sống nói chung, sự sinh trưởng, phát triển và hình thành năng suất, cây trồng nói riêng.

Điều kiện khí hậu nông nghiệp ở mỗi nơi là khác nhau và căn cứ vào sự khác nhau đó để phân chia thành các đơn vị khí hậu nông nghiệp được gọi là phân vùng khí hậu nông nghiệp. Nhiệm vụ của phân vùng khí hậu nông nghiệp là thực hiện phân chia các đơn vị khí hậu nông nghiệp thành vùng, tiểu vùng,... khác nhau bởi các chỉ tiêu khí hậu nông nghiệp và các điều kiện sản xuất nông nghiệp. Trong quá trình phân vùng có thể phát hiện ra được các vùng tuy rất xa nhau nhưng rất tương đồng về tài nguyên khí hậu nông nghiệp, rất bổ ích để di thực hoặc nhập nội giống cây trồng thích hợp [14-16]. Kết quả nghiên cứu [17] chỉ ra rằng các bản đồ phân vùng được xem là một trong những dịch vụ khí hậu nông nghiệp không thể thiếu trong quy hoạch và phát triển nông nghiệp. Tổ chức Khí tượng Thế giới $(\mathrm{WMO})$ cho rằng mục đích của phân vùng khí hậu nông nghiệp nhằm phát triển hệ thống trồng trọt thích nghi, tăng thu nhập cho nông dân, quản lý được rủi ro [18-20].

Tuyên Quang là tỉnh có tiềm năng phát triển nông nghiệp, theo định hướng phát triển của tỉnh trọng tâm trong giai đoạn tới bao gồm các nội dung cụ thể như: (1) Phát triển nông nghiệp theo hướng xây dựng các cánh đồng mẫu lớn; (2) Tập trung chuyển đổi cơ cấu kinh tế nông nghiệp, gia tăng giá trị sản phẩm trên một đơn vị diện tích; (3) Nâng cao năng suất, 
chất lượng nông sản, đạt hiệu quả cao và bền vững. Có thể thấy đây là chiến lược lâu dài trong phát triển nông nghiệp của tỉnh, do vậy, cần có những đánh giá đúng mức về tài nguyên KHNN, có những định hướng quy hoạch, mở rộng không gian phát triển trồng trọt, phát triển các vùng chuyên canh cây ăn quả có giá trị kinh tế hàng hoá một cách cụ thể. Trong đó, việc xác định những vùng có khả năng mở rộng sản xuất nông nghiệp, lựa chọn những loại cây trồng phát triển Thích nghi là những vấn đề cấp thiết. Cây trồng trong nông nghiệp có rất nhiều loại nên khi tiến hành nghiên cứu, đánh giá và phân vùng KHNN cho phát triển nông nghiệp ở Tuyên Quang, Bài báo đã lựa chọn một số cây trồng chủ lực, có thể thích hợp với điều kiện khí hậu địa phương, có giá trị kinh tế, ưu tiên các loại cây trồng đang là thế mạnh của tỉnh. Trong đó, tập trung vào 3 nhóm cây: Nhóm cây lương thực (lúa, ngô); Nhóm cây ăn quả (cam, nhãn); Nhóm cây công nghiệp (chè, mía).

Mục tiêu nghiên cứu của bài báo là áp dụng phương pháp phân vùng khí hậu nông nghiệp dựa trên công cụ LUSET (Land Use Suitability Evaluation Tool) [13] để phân vùng khí hậu nông nghiệp cho khu vực nghiên cứu tỉnh Tuyên Quang phục vụ mục đích chuyển đổi cơ cấu cây trồng.

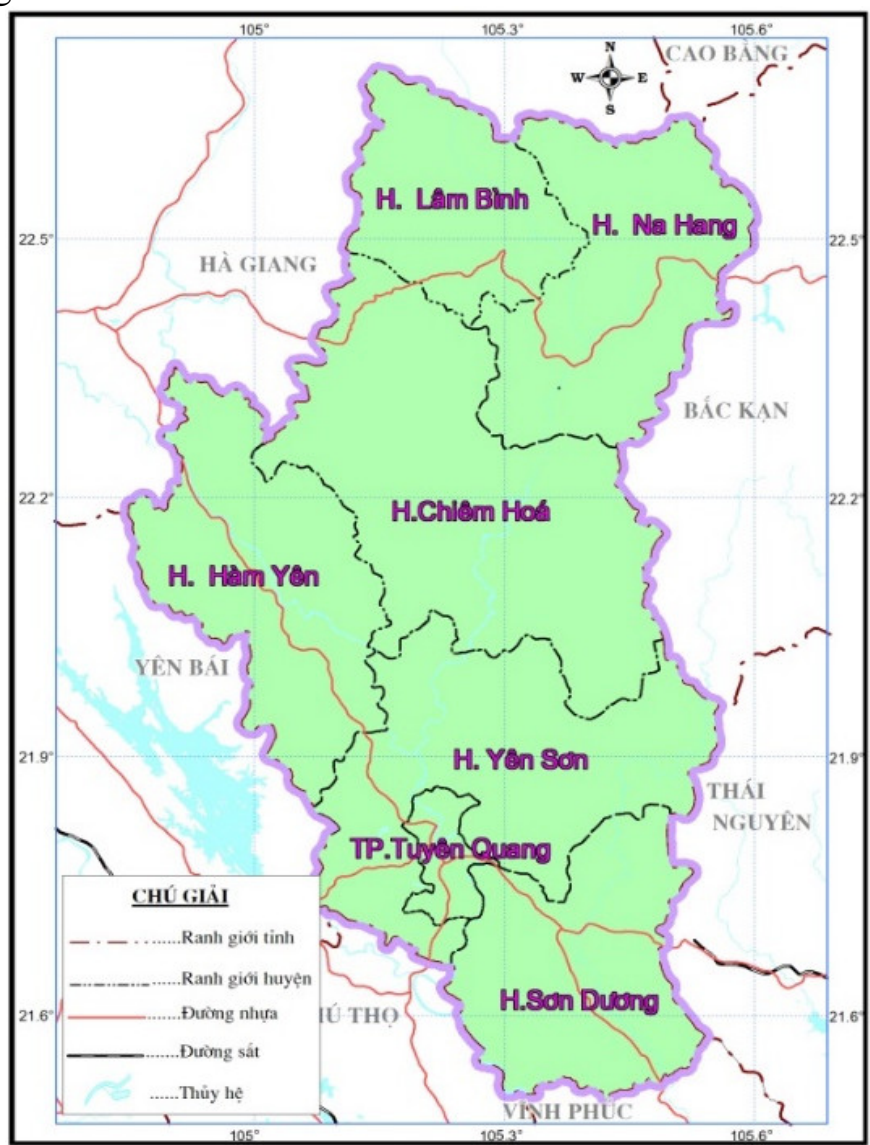

Hình 1. Sơ đồ khu vực nghiên cứu tỉnh Tuyên Quang.

\section{Dữ liệu sử dụng và phương pháp nghiên cứu}

\subsection{Dũ liệu sủ dụng}

Phân vùng khí hậu nông nghiệp tỉnh Tuyên Quang áp dụng cho lĩnh vực trồng trọt với một số cây trồng chính được nhóm tác giả nghiên cứu và sử dụng các số liệu đầu vào như sau:

- Dữ liệu khí tượng: Sử dụng dữ liệu nhiệt độ trung bình tháng, tổng lượng mưa trung bình tháng giai đoạn 1961-2018 của 15 trạm khí tượng vùng nghiên cứu và khu vực lân cận. 
- Dữ liệu bản đồ đất và địa hình: được sử dụng để tính toán độ sâu tầng đất và độ dốc địa hình, làm đầu vào cho việc đánh giá khả năng trồng trọt của các loại cây trồng.

\subsection{Phuoong pháp nghiên cúu}

- Phương pháp tính toán thống kê: Phương pháp này được áp dụng để tính toán các đặc trưng tài nguyên khí hậu nông nghiệp (ánh sáng, nhiệt, ẩm) từ số liệu các trạm quan trắc [10].

- Phương pháp nội suy: Sử dụng phương pháp nội suy để tính toán thông số độ dốc và phân bố theo không gian của dữ liệu khí tượng, dữ liệu tầng dày đất $[3,9]$.

- Phương pháp phân vùng khí hậu nông nghiệp dựa trên công cụ LUSET:

Công cụ LUSET (Land Use Suitability Evaluation Tool) [13], là công cụ tích hợp các Modulle tính toán bao gồm: Modulle về nhu cầu của cây trồng, Modulle về thông tin đơn vị đất và Modulle tính toán mức độ thích nghi. Công cụ LUSET cho phép tính toán sự thích nghi (OVS) riêng biệt của từng nhóm yếu tố và tích hợp tất cả nhóm yếu tố thành chỉ số OVS tổng hợp. Chỉ số thích nghi được xác định là điểm số thấp nhất trong tất cả các yếu tố được xem xét, OVS được tính theo công thức sau:

$$
\text { OVS }=\text { Min }(\mathrm{SF} 1, \mathrm{SF} 2, \mathrm{SF} 3 \ldots \mathrm{SFn})
$$

Trong đó OVS là giá trị thích nghi; SF1, SF2, SF3 ... SFn là điểm số thích nghi (dao động từ 0 đến 100 ) của $n$ yếu tố được chọn.

Quá trình tính toán chỉ số OVS được thực hiện theo 2 bước:

Bước 1: Tính toán OVS riêng biệt cho từng nhóm yếu tố (OVSg), OVSg có thể là nhóm đất-địa hình (độ dốc, độ sâu tầng đất), nhóm nhiệt độ (nhiệt độ trung bình theo tháng) hoặc nhóm nước (lượng mưa theo tháng và giả định không tưới).

$$
\mathrm{OVSg}=\mathrm{f}(\mathrm{S} 1, \mathrm{~S} 2, \ldots, \mathrm{Sn})
$$

Trong đó $\mathrm{S} 1, \mathrm{~S} 2, \ldots \mathrm{Sn}$ là điểm số thích nghi của các yếu tố trong một nhóm; $\mathrm{f}$ là hàm chức năng để tính toán sự thích nghi tổng thể (hàm Min).

Bảng 1. Các mức thích nghi tương ứng với nhân tố trọng số [13].

\begin{tabular}{cccc}
\hline Mức độ thích & Trọng số $=\mathbf{1}$ & Trọng số $=\mathbf{2}$ & Trọng số $=\mathbf{3}$ \\
\hline S1 & 85 & 95 & 100 \\
S2 & 60 & 65 & 70 \\
S3 & 40 & 45 & 50 \\
S4 & 0 & 10 & 15 \\
\hline
\end{tabular}

Bước 2: Tính toán sự Thích nghi tổng thể từ ba nhóm yếu tố (đất-địa hình, nhiệt, mưa)

$$
\mathrm{OVS}=\mathrm{f}(\mathrm{Sl}, \mathrm{St}, \mathrm{Sw})
$$

Trong đó $\mathrm{Sl}, \mathrm{St}, \mathrm{Sw}$ là giá trị OVSg tương ứng đối với các nhóm yếu tố đất-địa hình, nhiệt và mưa.

Trên cơ sở kết hợp giữa các loại thích nghi cho từng nhóm yếu tố OVSg và sử dụng phương pháp tối thiểu (công thức 1 và 2 ) để tạo ra một giá trị có khoảng dao động từ 0 đến 100 , giá trị này chính là điểm số OVS của yếu tố được xét đối với một cây trồng cụ thể trong một đơn vị diện tích. Từ kết quả này, sẽ phân loại được theo các mức độ thích nghi $\mathrm{S} 1, \mathrm{~S} 2, \mathrm{~S} 3$ và $\mathrm{N}$.

Bảng 2. Phân cấp mức độ thích nghi tổng thể [13].

\begin{tabular}{cccc}
\hline STT & Điểm số tổng & Ký hiệu & Mức độ thích \\
\hline 1 & $\geq 85$ & $\mathrm{~S} 1$ & Rất thích nghi \\
2 & $\geq 60$ và $<85$ & $\mathrm{~S} 2$ & Thích nghi \\
3 & $\geq 40$ và $<60$ & $\mathrm{~S} 3$ & Ít thích nghi \\
4 & $<40$ & $\mathrm{~N}$ & Không thích \\
\hline
\end{tabular}


Các kết quả đầu ra từ công cụ LUSET là bảng giá trị các điểm số tổng hợp đối với các loại cây trồng đã lựa chọn. Sau đó sử dụng phần mềm Arcgis để chồng ghép các bản đồ phân bố không gian cho các nhóm cây trồng đã lựa chọn để xác định bản đồ phân vùng khí hậu nông nghiệp chung cho tỉnh Tuyên Quang.

\section{Kết quả và thảo luận}

Nghiên cứu đã tính toán và phân vùng khí hậu nông nghiệp cho các cây trồng chủ lực của Tuyên Quang đó là: (1) Nhóm cây lương thực (lúa, ngô); (2) Nhóm cây ăn quả (bưởi, cam); (3) Nhóm cây công nghiệp (chè, mía). Kết quả phân vùng như sau:

a) Đối với nhóm cây luoong thưc (lúa, ngô)

Phần lớn các khu vực có địa hình thấp, độ dốc nhỏ ở địa bàn các huyện như: Chiêm Hóa, Hàm Yên, Sơn Dương, TP Tuyên Quang và Yên Sơn được đánh giá là rất thích nghi cho phát triển cây lúa. Một số khu vực ven sông suối của các huyện Lâm Bình và Na Hang với phân hạng thích nghi cũng có thể phát triển loại cây trồng này (Hình 2a).

Vùng rất thích nghi của cây ngô phân bố khá rộng, tập trung hầu hết diện tích ở các huyện Sơn Dương, Yên Sơn, TP Tuyên Quang, Chiêm Hóa, Hàm Yên. Khu vực Na Hang, Lâm Bình cũng có thể phát triển loại cây trồng này trên các vùng gò, đồi và ven sông suối có độ dốc dưới 300 (thuộc vùng thích nghi) (Hình 2b).

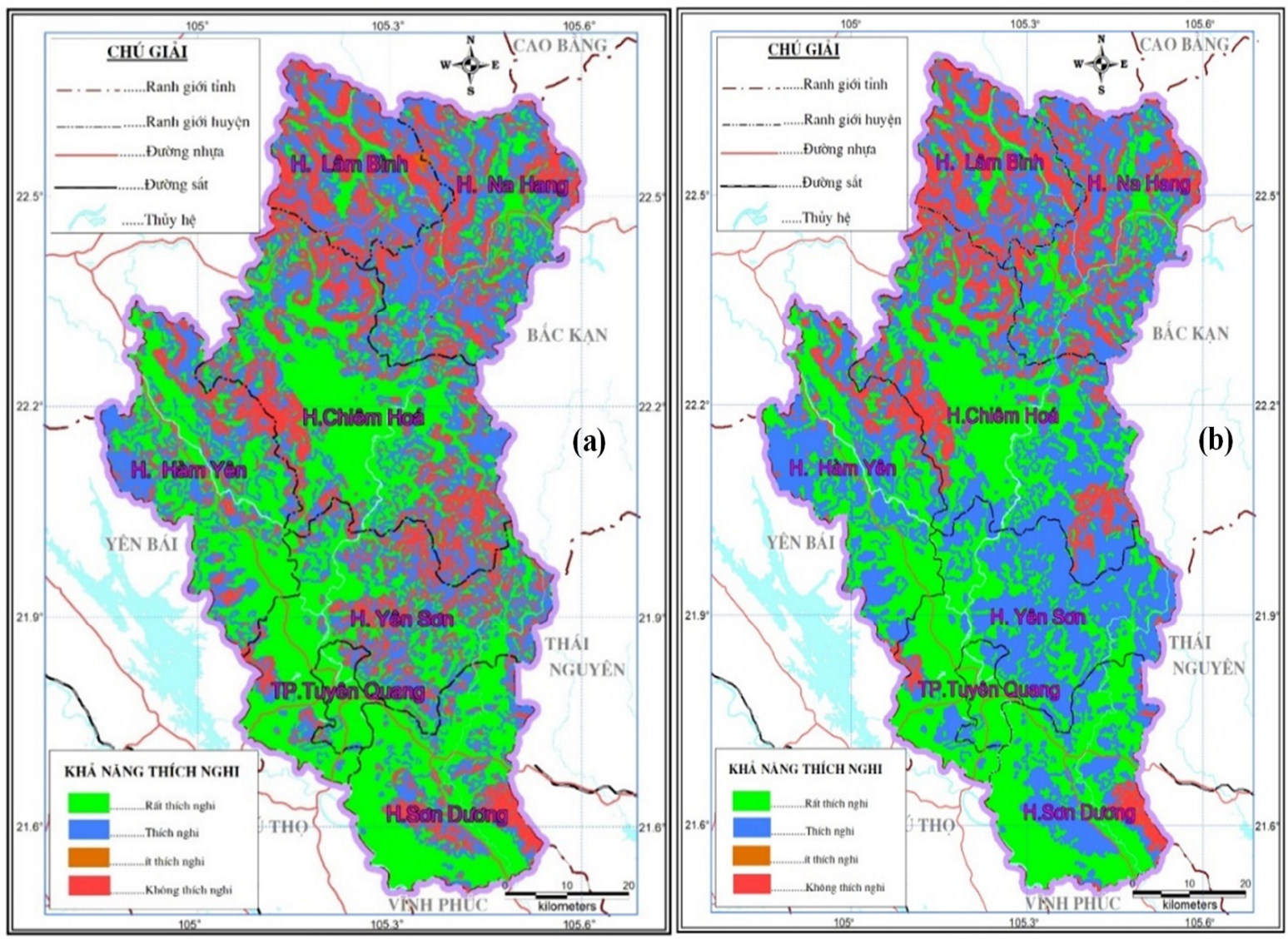

Hình 2. (a) Bản đồ phân vùng KHNN đối với cây lúa tỉnh Tuyên Quang; (b) Bản đồ phân vùng KHNN đối với cây ngô tỉnh Tuyên Quang.

\section{b) Đối với nhóm cây ăn quả (cam, nhãn)}

Vùng rất thích nghi đối với cây cam phân bố phần lớn ở các huyện Chiêm Hóa, Sơn Dương, Yên Sơn và TP Tuyên Quang và phần nhỏ ở khu vực thung lũng các huyện Lâm Bình và $\mathrm{Na}$ Hang . Vùng thích nghi phân bố rải rác khắp các huyện, nơi có địa hình thấp, độ dốc nhỏ, điều kiện khí hậu phù hợp với yêu cầu sinh thái của cây cam (Hình 3a). 
Khu vực rất thích nghi đối với cây nhãn phân bố tương tự như đối với cây cam, tuy nhiên phần diện tích thích nghi được mở rộng hơn ở khu vực huyện Lâm Bình và Na Hang (Hình 3b).

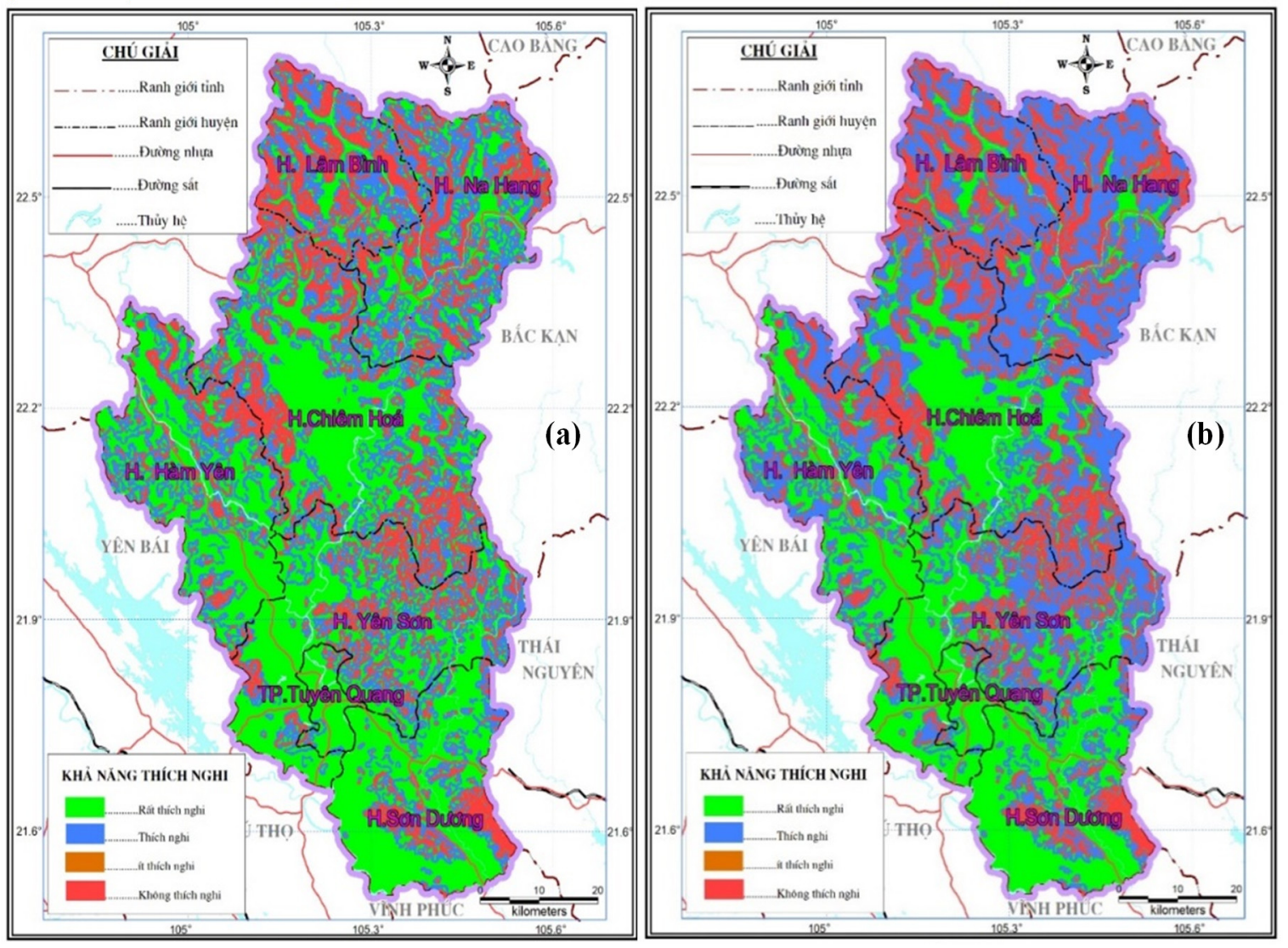

Hình 3. (a) Bản đồ phân vùng KHNN đối với cây cam tỉnh Tuyên Quang; (b) Bản đồ phân vùng KHNN đối với cây nhãn tỉnh Tuyên Quang.

c) Đối với nhóm cây công nghiệp (chè, mía)

Cây chè có thể thích nghi trên phần lớn diện tích lãnh thổ tỉnh Tuyên Quang, chỉ trừ những khu vực có địa hình cao và độ dốc lớn. Vùng rất thích nghi đối với cây chè phân bố ở các huyện Sơn Dương, Yên Sơn, Chiêm Hóa, Hàm Yên và TP Tuyên Quang (Hình 4a).

Khu vực rất thích nghi đối với cây mía phân bố ở các huyện Sơn Dương, Yên Sơn, Chiêm Hóa, Hàm Yên và TP Tuyên Quang. Một số khu vực có địa hình thấp của huyện Lâm Bình và $\mathrm{Na}$ Hang thuộc phân hạng thích nghi cũng thuận lợi cho cây mía phát triển (Hình 4b).

Từ các bản đồ phân vùng thành phần ở trên, nhóm nghiên cứu đã tiến hành phân tích và chồng xếp các bản đồ để cấu thành bản đồ phân vùng nông nghiệp cho trồng trọt của tỉnh Tuyên Quang. Kết quả cho thấy, Tuyên Quang được phân thành 4 vùng khí hậu nông nghiệp (Hình 5, Bảng 3): Vùng I (Vùng rất thích nghi-S1): có diện tích 281.406 ha chiếm $48,5 \%$ tổng diện tích, ưu tiên phát triển cây lương thực, hoa màu; Vùng II (vùng thích nghi-S2): có diện tích 164.088 ha chiếm $28,3 \%$ tồng diện tích, ưu tiên phát triển cây ăn quả, cây công nghiệp; Vùng III (vùng ít thích nghi-S3): 70.813 ha chiếm 12,2\% tổng diện tích, vùng này ít phù hợp cho phát triển nông nghiệp, vì vậy ưu tiên trồng rừng sản xuất; Vùng IV (vùng không thích nghi-N): có diện tích 64.375 ha chiếm $11,1 \%$ tổng diện tích toàn tỉnh, vùng này hoàn toàn không phát triển được nông nghiệp, hướng tốt nhất là bảo vệ rừng tự nhiên và trồng rừng phòng hộ. Như vậy, qua tính toán phân tích có thể thấy rằng, không gian phát triển nông nghiệp ở Tuyên Quang rất rộng, với gần $80 \%$ tổng diện tích toàn tỉnh phù hợp để phát triển nông nghiệp. Đây là lợi thế khá lớn để Tuyên Quang đẩy mạnh quy hoạch phát triển ngành nông nghiệp hàng hóa. 

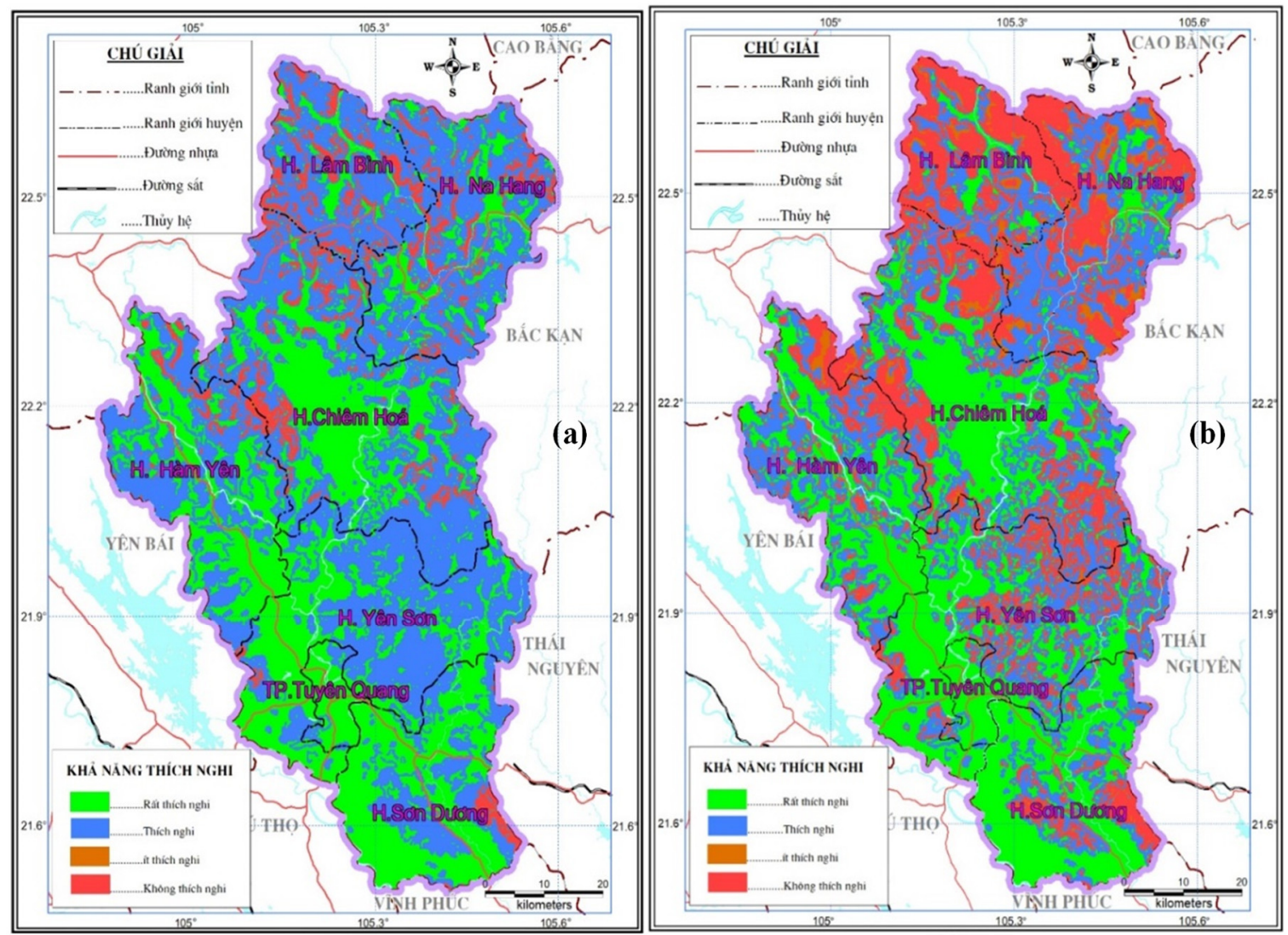

Hình 4. Bản đồ phân vùng KHNN đối với cây chè tỉnh Tuyên Quang; Bản đồ phân vùng KHNN đối với cây mía tỉnh Tuyên Quang.

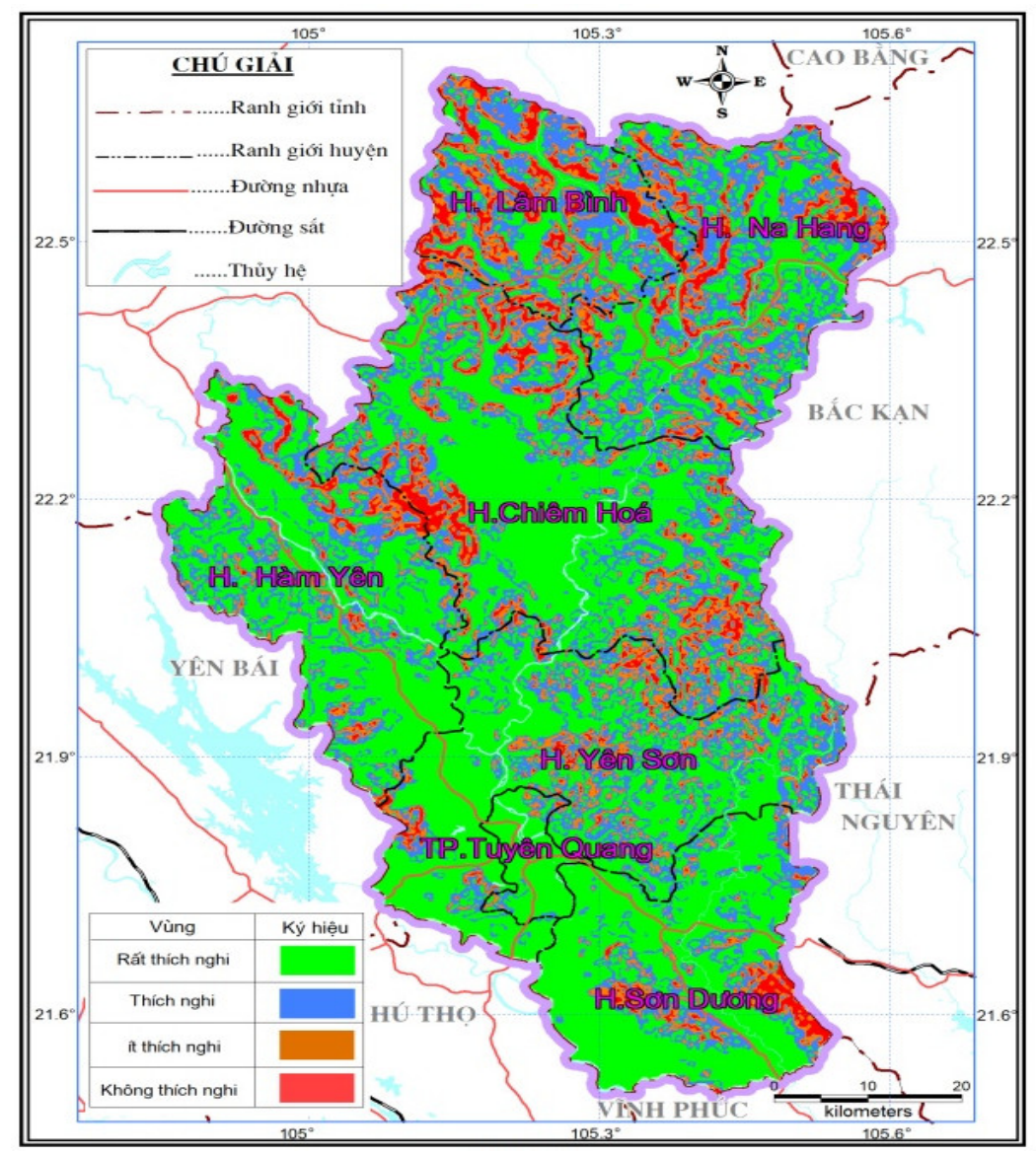

Hình 5. Bản đồ phân vùng khí hậu nông nghiệp tỉnh Tuyên Quang. 
Bảng 3. Khả năng trồng trọt trong các vùng KHNN tỉnh Tuyên Quang.

\begin{tabular}{|c|c|c|c|c|c|}
\hline Tên vùng & $\begin{array}{l}\text { Điểm số } \\
\text { tổng họ̣p }\end{array}$ & $\begin{array}{c}\text { Ký } \\
\text { hiệu }\end{array}$ & $\begin{array}{c}\text { Mức độ } \\
\text { thích nghi }\end{array}$ & $\begin{array}{c}\text { Diện tích } \\
\text { (ha) }\end{array}$ & Khuyến cáo khả năng trồng trọt \\
\hline I & $\geq 85$ & S1 & $\begin{array}{l}\text { Rất thích } \\
\text { nghi }\end{array}$ & 281.406 & $\begin{array}{l}\text { Các loại cây lương thực hàng năm như lúa, } \\
\text { ngô, khoai lang, lạc, đậu các loại và các } \\
\text { loại cây rau màu, cây ăn quả, cây công } \\
\text { nghiệp. }\end{array}$ \\
\hline II & $\begin{array}{c}\geq 60 \text { và } \\
<85\end{array}$ & S2 & Thích nghi & 164.088 & $\begin{array}{l}\text { Các loại cây ăn quả có múi, cây ăn quả } \\
\text { hàng năm, lâu năm như nhãn, xoài, } \\
\text { hồng,...các cây công nghiệp như mía, chè. }\end{array}$ \\
\hline III & $\begin{array}{c}\geq 40 \text { và } \\
<60\end{array}$ & S3 & Ít thích nghi & 70.813 & Phát triển trồng rừng sản xuất \\
\hline IV & $<40$ & $\mathrm{~N}$ & $\begin{array}{l}\text { Không thích } \\
\text { nghi }\end{array}$ & 64.375 & $\begin{array}{l}\text { Rừng tự nhiên và rừng phòng hộ đầu } \\
\text { nguô̂n, đảm bảo cân bằng hệ sinh thái. }\end{array}$ \\
\hline
\end{tabular}

\section{Kết luận}

Kết quả phân vùng khí hậu nông nghiệp tỉnh Tuyên Quang đã thể hiện được phân bố không gian các vùng thich nghi cho phát triển nông nghiệp.Việc tích hợp các thông tin về điều kiện khí hậu, địa hình, thổ nhưỡng để xây dựng bản đồ phẩn vùng khí hậu nông nghiệp chung và phân vùng KHNN đối với từng nhóm cây trồng tỉnh Tuyên Quang là cơ sở khoa học quan trọng trong việc quy hoạch không gian canh tác và phát triển các loại cây trồng, trong đó trọng tâm là các cây lương thực, cây công nghiệp và cây ăn quả. Bản đồ phân vùng khí hậu nông nghiệp cần có sự kết hợp với dịch vụ khí hậu trong nông nghiệp và kiến thức bản địa để đưa ra khuyến cáo thực tê và phù hợp. Các thông tin dự báo thời tiết, dự báo mùa là các yếu tố cần thiết để điều chỉnh cơ cấu cây trồng, lịch mùa vụ. Dự báo thời tiết hàng ngày, theo tuần cần được cập nhật và cung cấp thường xuyên cho cán bộ nông nghiệp và người dân để việc áp dụng kết quả nghiên cứu này hiệu quả hơn.

Đóng góp của tác giả: Xây dựng ý tưởng nghiên cứu: N.T.L., N. D.T.; Lựa chọn phương pháp nghiên cứu: N.T.L., N. D.T.; Xử lý số liệu: N. D.T.; Tính toán: N.T.L., N. D.T.; Phân tích kết quả: N.T.L.; Viết bản thảo bài báo: N.T.L., N. D.T.; Chỉnh sửa bài báo: N.T.L.

Lời cảm ơn: Nghiên cứu này được thực hiện dưới sự tài trợ của đề tài nghiên cứu khoa học cấp tỉnh, mã số ĐT.08-2018.

Lời cam đoan: Tập thể tác giả cam đoan bài báo này là công trình nghiên cứu của tập thể tác giả, chưa được công bố ở đâu, không được sao chép từ những nghiên cứu trước đây; không có sự tranh chấp lợi ích trong nhóm tác giả.

\section{Tài liệu tham khảo}

1. Giai, N.S. Bước đầu đánh giá mức độ sử dụng tài nguyên khí hậu nông nghiệp của các cây trồng chính ở 3 vùng trọng điểm của Việt Nam. Báo cáo kể quả đề tài nghiên cứu khoa học, Viện KTTV, Hà Nội, 1992.

2. Hạnh, T.Đ.; Điếm, Đ.V.; Viết, N.V. Lý thuyết khai thác tài nguyên khí hậu nông nghiệp; Nhà xuất bản Nông nghiệp Hà Nội, 1997.

3. Khảm, D.V.; Tâm, T.T.; Quyền, N.H.; Sơn, N.H. Phương pháp xây dựng bản đồ phân vùng an toàn sương muối, nhiệt độ thấp khu vực Tây Bắc. Hội thảo Quốc gia về Khí tượng Thủy văn Môi trường và Biến đổi khí hậu, Viện KTTV, 2013.

4. Khảm, D.V.; Quyền, N.H. Đánh giá đặc điểm khí hậu và điều kiện khí hậu nghiệp huyện Ba Bể. Báo cáo hợp đồng tư vấn của CARE, 2015.

5. Khảm, D.V. Nghiên cứu phân vùng sương muối và xây dựng mô hình giám sát, cảnh báo sương muối, nhiệt độ thấp phục vụ phát triển kinh tê xã hội, phòng tránh thiên tai ở các tỉnh miền núi, trung du phía đông bắc bộ. Báo cáo tổng kết đề tài cấp Bộ. Viện KTTV\&BĐKH, 2017.

6. Lan, H.N. Điều kiện khí hậu nông nghiệp và cơ cấu mùa vụ của một số cây trồng chính ở Nam Bộ. Tập công trình Phân viện KTTV phía Nam, 1993. 
7. Liem, N.V. Điều tra khảo sát và đánh giá điều kiện khí hậu nông nghiệp phục vụ tái định cư thuỷ điện Sơn La tại các vùng $\mathrm{Ba}$ Chà, Mường Toong - Mường Nhé tỉnh Điện Biên. Báo cáo kết quả Dự án, Viện KTTV, 2006.

8. Quang, L.V. Tìm các chỉ tiêu khí hậu nông nghiệp tổng hợp cho một số cây trồng chủ yêu ở Nam Bộ. Tập báo cáo khoa học chương trình nghiên cứu khí hậu nông nghiệp đồng bằng Nam Bộ, Phân viện KTTV, 1992.

9. Quyển, N.H.; Khảm, D.V.; Tâm, T.T.; Trang, N.T. Nội suy dữ liệu không gian băng thông tin viễn thám và GIS phục vụ xây dựng bản đồ sương muối và nhiệt độ thấp vùng Tây Bắc. Hội thảo Quốc gia về Khí tượng Thủy văn Môi trường và Biến đồi khí hậu, Viện KTTV, 2013.

10. Tân, P.V. Phương pháp thống kê trong khí hậu, NXB Đại học Quốc gia Hà Nội, 2005.

11. Toàn, P.N.; Thanh, V. Nghiên cứu khí hậu nông nghiệp và phân vùng khí hậu nông nghiệp Nam Bộ. Phân Viện KTTV phía Nam, 1992.

12. Viêt, N.V. Tài nguyên khí hậu nông nghiệp việt Nam. Nhà xuất bản nông nghiệp Hà Nội, 2009, tr. 406.

13. Yen, B.T.; Pheng, K.S.; Hoanh, C.T. LUSET User's guide. International Rice Research Institute, 2006, pp. 15.

14. Jiang, A.L. Climate and Agriculture in China. Springer, Dordrecht, 1997. https://doi.org/10.1007/978-94-017-1055-8_13.

15. Huard, F.; Paranaud, V. Agrometeorological database management strategies and tool in France. WMO \& USDA, 2001. https://doi.org/10.1007/978-3-540-746980106.

16. Jagtap, S.S. Planning sustainable agriculture using agroclimatic database. WMOCagM. 2001, pp. 85. https://library.wmo.int/doc_num.php?explnum_id=9164.

17. Stigter, K. Applied Agrometeorology, Berlin, Germany: Springer, 2010, pp. 1100. https://doi.org/10.1007/978-3-540-74698-0.

18. Mischenko, Z.A. Agroclimatic mapping of the continents. WMO, CAgM report 1984, 23, pp. 1-83. https://library.wmo.int/doc_num.php?explnum_id=7033.

19. Patel. N.R. Remote sensing and GIS application in agro-ecological zoning. AGM8, WMO/TD-No. 1182, 2003. http://www.wamis.org/agm/pubs/agm8/Paper11.pdf.

20. William, G.D.V. Agroclimatic resource analysis on ex. using an index derived and applied for Canada. Agri-Meteorology 1983, 28, 31-47. https://doi.org/10.1016/0002-1571(83)90021-3.

\title{
Research on agricultural climate zoning for the purpose of crop restructuring in Tuyen Quang province
}

\author{
Nguyen Thi Lieu ${ }^{*}$, Nguyen Dang Tien ${ }^{2}$ \\ ${ }^{1}$ Institute of Meteorology, Hydrology and Climate Change; lieuminh2011@gmail.com \\ ${ }^{2}$ Red Star University; dangtien.dhsd@gmail.com
}

\begin{abstract}
Applied Research on climate is one of the highly practical research directions for sustainable economic development. At the same time, it makes contribution to the rational exploitation and use of natural resources, protecting the environment for certain territory in order to obtain efficient agricultural production. The article applies the method of zoning agro-climate by Luset tool parameterized with meteorological, pedigree and topographic factors. Calculation results show that: Tuyen Quang province is divided into 4 main agro-climatic regions: the highly adaptive area is about 281,406 ha, accounting for $48.5 \%$ of the total area of the province; The adaptive area is about 164,088 ha, accounting for $28.3 \%$; Less suitable area is about $70,813 \mathrm{ha}$, accounting for $12.2 \%$ and non-adapted area is about $64,375 \mathrm{ha}$, accounting for $11.1 \%$.
\end{abstract}

Keywords: Zoning; Agro-climatology; Luset Tool. 